Original Research Paper

\title{
Aplikasi Pemeliharaan Anakan Kuda Laut menggunakan Akuarium pseudoKreisel di Desa Ekas Buana, Jerowaru, Lombok Timur
}

\author{
Dewi Nur'aeni Setyowati ${ }^{1}$, Nunik Cokrowati ${ }^{1}$, Maedi Mahdalena ${ }^{1}$ \\ ${ }^{1}$ Jurusan Perikanan dan Ilmu Kelautan, Universitas Mataram, Mataram, Indonesia
}

DOI: https://doi.org/10.29303/jpmpi.v4i2.820

Sitasi: Setyowati, D. N., Cokrowati, N., \& Mahdalena, M. (2021). Aplikasi Pemeliharaan Anakan Kuda Laut menggunakan Akuarium pseudoKreisel di Desa Ekas Buana, Jerowaru, Lombok Timur. Jurnal Pengabdian Magister Pendidikan IPA, 4(2)

\section{Article history}

Received: 29 Maret 2021

Revised: 29 Mei 2021

Accepted: 29 Juni 2021

*Corresponding Author:

Dewi Nur'aeni Setyowati,

Universitas Mataram, Mataram,

Indonesia

Email: dewins@unram.ac.id

\begin{abstract}
Desa Ekas Buana merupakan desa yang potensial untuk budidaya laut. Di desa tersebut, kuda laut dapat diperoleh melalui penangkapan. Kegaiatan penangkapan yang berlebih dapat menyebabkan berkurangnya populasi kuda laut di alam. Oleh karena itu dibutuhkan penerapan teknologi budidaya kuda laut. Pemeliharaan anakan kuda laut dapat menggunakan akuarium pseudoKreisel. Tujuan dari kegiatan pengabdian ini adalah untuk penerapan teknologi pemeliharaan anakan kuda kaut menggunakan akuarium pseudoKreisel. Metode pengabdian adalah dengan melakukan peningkatan wawasan pengetahuan ke masyarakat tentang budidaya anakan kuda laut menggunakan pseudoKreisel, penerapan budidayanya dan pendampingan terhadap kegiatan budidaya yang dilakukan oleh masyarakat. Hasil pengabdian menunjukkan pengetahuan masyarakat tentang buddiaya anakan kuda laut meningkat dengan ikut terlibat dalam budidaya anakan kuda laut menggunakan akuarium pseudo kriesel
\end{abstract}

Keywords: buddiaya, kuda laut, akuarium pseudoKreisel, Ekas Buana

\section{Pendahuluan}

Desa Ekas Buana merupakan desa yang berada di pinggir Teluk Ekas dengan. Mata pencaharian di desa tersebut antara lain adalh budidaya rumput laut, budidaya ikan laut dan penangkapan ikan, diantaranya kuda laut. Harga kuda laut dapat mencapai Rp.15.000/ekor. Sedangkan untuk $1 \mathrm{~kg}$ kuda laut kering dapat mencapai Rp.5.500.000,- per kg (Setyowati dan Cokrowati, 2018). Harga kuda laut yang tinggi dapat mengancam keberadaan kuda laut di alam. Oleh karena itu perlu diterapkan teknologi budidaya kuda laut. Salah satu kendala dalam budidaya kuda laut adalah dalam keberhasilan pemeliharaan anakan. Anakan kuda laut masih rentan terjebak di permukaan air. Jika anakan kuda laut sudah terjebak di permukaan air, maka anakan tersebut tidak mampu turun ke dalam air dan tidak mampu untuk mengambil pakan sehingga anakan kuda laut mengalami kematian. Penelitian Setyowatiet al. (2017) telah melakukan pemeliharaan indukan kuda laut di bak bulat dan bak persegi panjang. Namun tingkat kelangsungan hidup sebesar $75 \%$ untuk bak bundar dan $50 \%$ untuk bak persegi panjang. Sedangkan anakan yang dihasilkan dari pemeliharaan belum optimal. Penelitian Cartagena (2014) menunjukkan bahawa pemeliharaan anakan kuda laut dengan menggunakan akuarium pseudoKreisel menunjukkan tingkat kelangsungan hidup yang lebih tinggi dibandingkan dengan anakan kuda laut yang dipelihara di akuarium berbentuk bulat 
maupun persegi panjang. Oleh karena itu, penerapan budidaya anakan kuda laut mengguaakn akuarium pseudoKriesel perlu untuk dilakukan.

\section{Metode}

Kegiatan pengabdian masyarakat ini dilaksanakan di Desa Ekas Buana, Kecamatan Jerowaru, Kabupaten Lombok Timur pada bulan April-September 2021. Metode yang digunakan pada kegiatan ini adalah:

1. Sosialisasi kegiatan pengabdian

Sosialisasi dilakukan kepada masyarakat dan aparat Desa Ekas Buana terkait dengan kegiatan pemeliharaan anakan kuda laut menggunakan akuarium pseudoKreisel.

2. Penyuluhan

Penyuluhan dilakukan terhadap masyarakat Desa Ekas Buana yang rata-rata bekerja sebagai pembudidaya rumput laut dan nelayan. Penyuluhan dilakukan untuk memberikan informasi teknologi budidaya anakan kuda laut menggunakan akuarium pseudoKreisel. Dalam kegiatan penyuluhan menggunakan metode pembelajaran orang dewasa dengan tim perguruan tinggi sebagai fasilitator

3. Penerapan budidaya anakan kuda laut menggunakan akuarium pseudoKreisel

Untuk meningkatkan pemahaman masayarakat Desa Ekas Buana, maka dibuat demplot dengan pemeliharan anakan kudal laut menggunakan akuarium pseudoKreisel.

4. Pendampingan

Pendampingan dilakukan oleh tim pengabdian dengan menempatkan mahasiswa selama 1 bulan untuk mendampingi masyarakat Desa Ekas Buana dalam melakukan kegiatan pemeliharaan anakan kuda laut menggunakan akuarium pseudoKreisel. Selain itu, tim pengabdian juga melakukan komunikasi secara aktif terhadap masyarakat Desa Ekas Buana dalam pendampingan budidaya anakan kuda laut.

\section{Hasil dan Pembahasan}

Masyarakatt Desa Ekas Buana diberikan pemahaman tentang pemeliharaan kuda laut menggunakan akuarium pseudoKreisel. Selain itu, masyarakat juga diberikan praktek membuat dan memelihara anakan kuda laut menggunakan akuarium pseudoKreisel. Desain akuarium yang dibuat berdasarkan penelitian Cartagena (2014) dengan modifikasi menggunakan bahan-bahan yang lebih sederhana dan mudah ditemukan di Lombok.
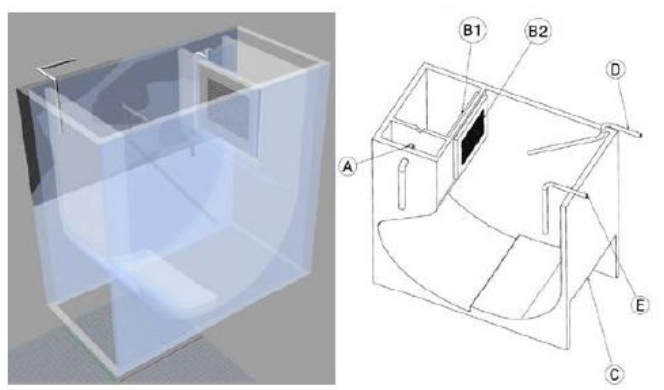

Gambar 1. Desain Akuarium pseudoKreisel oleh Cartagena (2014)

Adapun alat dan bahan yang digunakan antara lain, kaca untuk dijadikan akuarium, lem kaca, aerator,pompa.
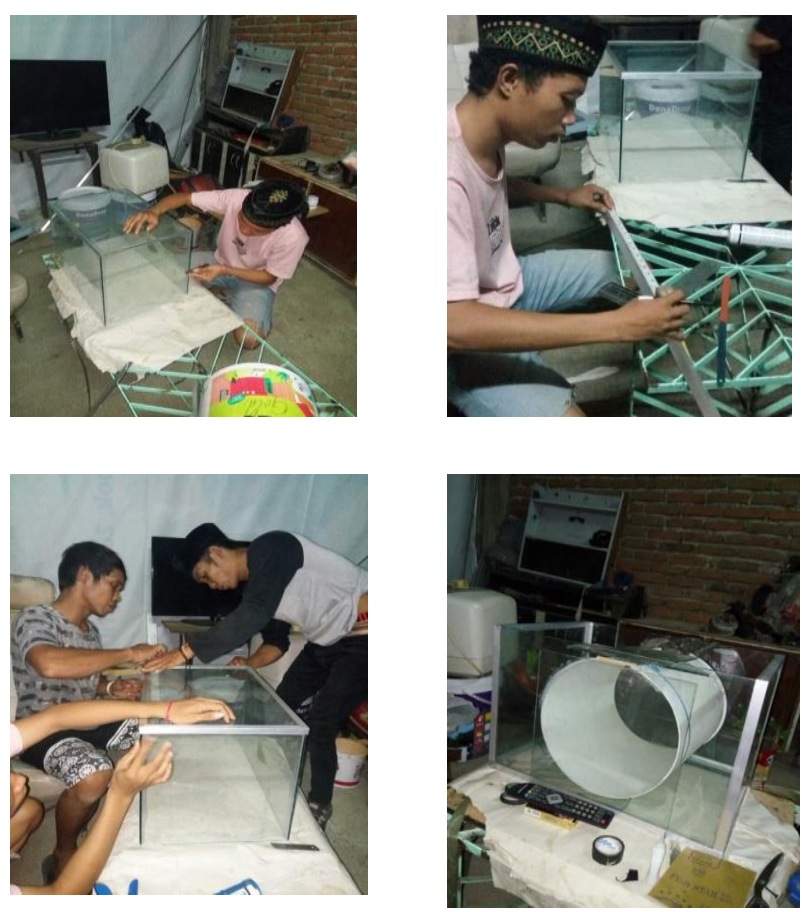

Gambar. Proses Pembuatan Akuarium pseudoKreisel

Setelah akuarium selesai dibuat, maka dapat digunakan untuk memelihara anakan kuda laut. Anakan kuda laut akan bergerak memutar di akuarium sehingga tidak akan terperangkap di permuk.aan air. Aerasi dibuat pelan sehingga gerakan memutar tidak cepat. Pemeliharaan anakan kuda laut melibatkan masyarakat Desa Ekas Buana 
dengan 1 rumah penduduk dijadikan sentra pemeliharaan. Selama proses pemeliharaan, masyarakat Desa Ekas Buana menjadi tahu cara penanganan anakan kuda laut, metode pemeliharaan anakan kuda laut dengan akuarium pseudoKreisel karena terlibat langsung dlam proses pemeliharaan.

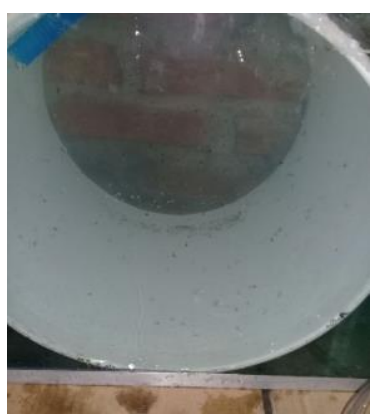

Gambar. Anakan Kuda Laut di Akuarium pseudoKreisel

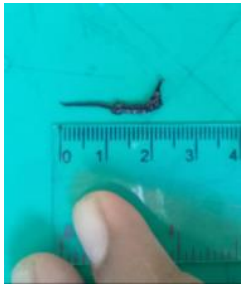

Gambar. Anakan Kuda Laut

Hasil penerapan budidaya anakan kuda laut dengan menggunakan akuarium pseudoKreisel menunjukkan kelangsungan hidup yang baik sehingga dapat diaplikasikan untuk pemeliharaan anakan kuda laut ke depan. Selain itu, akuarium pseudoKreise yang digunakan adalah akuarium yang sederhana dengan bahan-bahan yang mudah ditemukan di Lombok. Walaupun begitu, masih perlu tersu dilakukan optimasi pemeliharaan agar menghasilkan pertumbuhan anakan kuda laut yang optimal dengan memperhatikan padat tebar aakan kuda laut di akuarium, pakan, dan pergantian air.

\section{Kesimpulan}

Hasil kegiatan pengabdian dengan
penerapan budidaya anakan kuda laut
menggunakan akauriaum pseudoKreisel dapat
mejadi alternatif teknologi untuk pemeliharaan
anakan kuda laut. Bahan-bahan yang digunakan
untuk pembuatan akuarium pseudoKreisel juga merupakan bahan yang mudah ditemukan di masyarakat Lombok sehingga memudahkan dalam penerapannya. Dalam aplikasinya, pemeliharaan anakan kuda laut dengan akuarium pseudoKreisel perlu juga memperhatikan jumlah padat tebar, jumlah pakan dan kualitas air selama pemeliharaan.

\section{Saran}

Saran untuk pengembangan ke depan adalah melakukan optimasi peggunaan akuarium pseudoKreisel dari jumlah anakan yang ditebar, kekuatan gerakan air, pakan dan kualitas air yang optimal.

\section{Ucapan Terima Kasih}

Penulis mengucapkan terima kasih kepada Direktorat Riset dan pengabdian Masyarakat, Direktorat jenderal Penguatan Riset dan Pengembangan, Kementerain Riset, teknologi dan Pendidikan Tinggi yang telah memberi dukungan finansial terhadap pengabdian ini.

\section{Daftar Pustaka}

Setyowati, D.N., Cokrowati, N. 2018. PKM kelompok pembudidaya kuda laut skala rumah tangga di Desa ekas Buana, Kecamatan Jerowaru, Kabupaten Lombok Timur, provinsi Nusa tenggara Barat. Laporan Akhir Program Kemitraan Masyarakat. Mataram.

Setyowati, D.N., Diniarti, N., Cokrowati, N. 2017. Seahorse (Hippocampus sp.) Broodstock Culture in Controlled Tank. Proceeding of $2^{\text {nd }}$ International Conference on Science and Technology in The Tropic. Mataram. August 23-24.

Cartagena, A.B. 2014. Rearing of the seahorse Hippocampus guttulatus: key factors involved in growth and survival. Phd Thesis. Marine Ecology Doctorate Programme. Universitat de les Illes Ballears. http://www.tdx.cat/bitstream/handle/1080 $\underline{3 / 145616 / \text { tabc1de1.pdf?sequence }=1}$ 